\begin{tabular}{|c|c|c|c|c|c|c|}
\hline \multirow{4}{*}{ Impact Factor: } & ISRA (India) & $=3.117$ & SIS (USA) & $=0.912$ & ICV (Poland) & $=6.630$ \\
\hline & ISI (Dubai, UAE & $=\mathbf{0 . 8 2 9}$ & РИНЦ (Russia & $=0.156$ & PIF (India) & $=1.940$ \\
\hline & GIF (Australia) & $=0.564$ & ESJI (KZ) & $=\mathbf{5 . 0 1 5}$ & IBI (India) & $=4.260$ \\
\hline & JIF & $=1.500$ & SJIF (Morocco & $=5.667$ & OAJI (USA) & $=0.350$ \\
\hline
\end{tabular}

\begin{tabular}{|c|c|}
\hline \multicolumn{2}{|c|}{$\begin{array}{l}\text { SOI: } \underline{1.1 / \mathrm{TAS}} \text { DOI: } 10.15863 / \mathrm{TAS} \\
\text { International Scientific Journal } \\
\text { Theoretical \& Annlied Science }\end{array}$} \\
\hline p-ISSN: 2308-4944 (print) & e-ISSN: 2409-0085 (online) \\
\hline Year: 2019 & Volume: 69 \\
\hline Published: 23.01.2019 & http://T-Science.org \\
\hline
\end{tabular}

SECTION 32. Jurisprudence.
QR - Issue

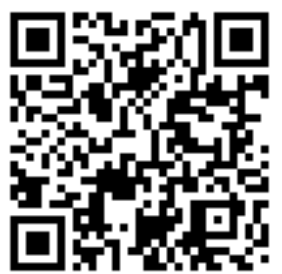

QR - Article

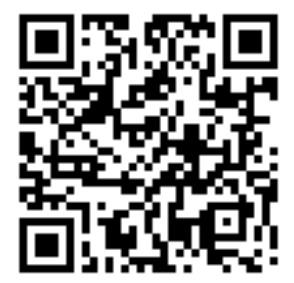

Aibek Bolotbekovich Akhmatov professor of the Administrative Law and Administrative Activities Department of the Academy of the Ministry of Internal Affairs of the Kyrgyz Republic, Candidate of Juridical Sciences

Nuriya Kubanichbekovna Mamatazizova head of the Administrative Law and Administrative Activities Department of the Academy of the Ministry of Internal Affairs of the Kyrgyz Republic, Doctor of Juridical Sciences, Assistant Professor, colonel of militia

\title{
PRE-TRIAL PROCEEDINGS ON THE NEW CRIMINAL PROCEDURE LEGISLATION OF THE KYRGYZ REPUBLIC AS THE BEGINNING OF CRIMINAL PROCEDURE: PROBLEMS AND SOLUTIONS
}

Abstract: This article analyzes the norms of the articles of the Criminal Procedure Code of 1999 and the newly adopted Code of Criminal Procedure of the Kyrgyz Republic on the issues of commencement of pre-trial proceedings. In the article, the author attempted to carry out a comparative legal analysis and identify the shortcomings and advantages of pre-trial proceedings and give powerful arguments in favor of the abolition of the criminal case initiation stage.

Key words: pre-trial proceedings, the beginning of criminal procedure, the new criminal procedure code of the Kyrgyz Republic, the beginning of the investigation, pre-investigation check, the criminal process.

Language: Russian

Citation: Akhmatov, A. B., \& Mamatazizova, N. K. (2019). Pre-trial proceedings on the new criminal procedure legislation of the Kyrgyz republic as the beginning of criminal procedure: problems and solutions. ISJ Theoretical \& Applied Science, 01 (69), 201-205.

Soi: http://s-o-i.org/1.1/TAS-01-69-25 Doi: erossef https://dx.doi.org/10.15863/TAS.2019.01.69.25

\section{ДОСУДЕБНОЕ ПРОИЗВОДСТВО ПО НОВОМУ УГОЛОВНО-ПРОЦЕССУАЛЬНОМУ ЗАКОНОДАТЕЛЬСТВУ КЫРГЫЗСКОЙ РЕСПУБЛИК КАК НАЧАЛО УГОЛОВНО- ПРОЦЕССУАЛЬНОЙ ДЕЯТЕЛЬНОСТИ: ПРОБЛЕМЫ И ПУТИ РЕШЕНИЯ}

Аннотация: в данной статье анализируются нормы статей УПК 1999 года и ново принятого УПК КР, по вопросам начала досудебного производства. В статье, автор предпринял попьтку провести сравнительно-правовой анализ и выявить недостатки и преимуществв досудебного производства и привести весомые аргументы в пользу упразднения стадии возбуждения уголовного дела.

Ключевые слова: досудебное производство, начало уголовно-процессуальной деятельности, новый уголовно-прочессуальный кодекс Кыргызской Республики, начало расследования, до следственная проверка, уголовный проиесс.

\section{Introduction}

В течение пятилетнего периода, начиная с 2013 года, государство решительно направило свой курс на проведение реформ во всех сферах общественной жизни: социальной, экономической, политической, уголовной и т.д.
Безусловно, подобное решение государство обусловлено различными факторами, прежде всего, социально-экономическими, которые и выступают базисом всего остального. Законы, которые были приняты после распада СССР и 


\begin{tabular}{|c|c|c|c|c|c|c|}
\hline \multirow{4}{*}{ Impact Factor: } & ISRA (India) & $=3.117$ & SIS (USA) & $=0.912$ & ICV (Poland) & $=6.630$ \\
\hline & ISI (Dubai, UAE & $=0.829$ & РИНЦ (Russia) & $=0.156$ & PIF (India) & $=1.940$ \\
\hline & GIF (Australia) & $=0.564$ & ESJI (KZ) & $=\mathbf{5 . 0 1 5}$ & IBI (India) & $=4.260$ \\
\hline & JIF & $=1.500$ & SJIF (Morocco) & $=5.667$ & OAJI (USA) & $=0.350$ \\
\hline
\end{tabular}

приобретения Кыргызской Республикой суверенитета, в прямом смысле слова изжили себя, они уже не соответствуют тем реалиям жизни, в которых живет общество. Работа в этом направлении велась путем создания различных рабочих групп, комиссий по разработке проектов законодательств. При этом следует отметить, что основное внимание было уделено реформированию правоохранительных и судебных органов. Так, с подписанием Указа Президента №147 от 12 августа 2012года «О мерах по совершенствованию правосудия в Кыргызской Республике» был сделан первый шаг судебной реформы, направленный на обеспечение защиты прав, свобод и законных интересов граждан в соответствии с международными стандартами. И в рамках данной судебной реформы был разработан проект нового Уголовно-процессуального кодекса Кыргызской Республики, который действует с 30 июня 1999 года, естественно с многочисленными изменениями и дополнениями. После многочисленных обсуждений, новый УПК [1] был принят ЖК и подписан Президентом Кыргызской Республики, но с оговоркой, что он будет введен в действие с 1 января 2019 года. Этот промежуток времени предназначалось для подготовки сотрудников правоохранительных органов, их обучению, переосмыслению норм нового УПК КР.

\section{Materials and Methods}

Новый Уголовно-процессуальный кодекс существенно отличался от кодекса 1999 года , как по структуре, так и по содержанию. Содержит очень много новелл, которые требуют грамотного, профессионального теоретического осмысления для последующей их практической реализации.

Одним из существенных новелл является упразднение стадии возбуждения уголовного дела, которое сразу же породило множество вопросов, как со стороны практических работников, так и теоретиков. При разработке проекта нового уголовно-процессуального кодекса особенно в части проектирования новой модели начала расследования, в основном был перенят опыт европейских государств, которые в отличие от постсоветских стран давно исключили стадию возбуждения уголовного дела.

Стадия возбуждения уголовного дела всегда была одной из остро дискуссионных вопросов. Ряд ученых считали, что это «лишняя волокита», формальный бюрократизм [2, с. 56], [3, с. 64]. Так, по мнению сторонников подобной реформы это позволит отказаться от доследственной проверки и с самого начала производства собирать «полноценные» доказательства с использованием всего арсенала средств доказывания, предусмотренного уголовнопроцессуальным законом. Также упразднение в уголовно-процессуальном законе самой возможности вынесения решения об отказе в возбуждении уголовного дела прекратит незаконную практику принятия сотрудниками правоохранительных органов незаконных и необоснованных постановлений об отказе в возбуждении уголовных дел [4, с. 17].

Некоторые оппоненты, напротив выступали за существование данной стадии, даже придавая ей обязательный характер [5, с. 34]. Они отмечали, что стадия возбуждения уголовного дела, завершаемая двумя основными решениями противоположной направленности - возбудить дело или отказать в его возбуждении - играет роль своеобразного фильтра, который устраняет из сферы деятельности органов предварительного расследования все то, что не влечёт за собой уголовной ответственности. Именно это обстоятельство является основным предназначением данного этапа досудебного производства. Снятие подобного барьера моментально загрузит правоохранительные органы огромным количеством уголовных дел, которые неизбежно закончатся ничем, так как отсутствует сам состав преступления [6, с. 168]. Еще в 2010 года в Форуме по уголовному правосудию для Центральной Азии, участникиэксперты многих государств высказывали мнение, что «возбуждение уголовного дела в государствах Центральной Азии и большинстве других стран постсоветского пространства знаменует начало уголовного расследования. Тем не менее, еще до формального возбуждения уголовного дела полиция проводит доследственную проверку, в результате которой могут быть нарушены права лиц, не имеющих при этом никаких процессуальных гарантий, в связи с отсутствием формального статуса в уголовном процессе. Стадия возбуждения уголовного дела-«советская модель двойного расследования», которая давно устарела и требует скорейшего реформирования» [7, с. 51]. Поддерживая данную точку зрения, руководитель программ и член правления Центра политикоправовых реформ Украины, Олександр Банчук, отметил, что «формальное возбуждение уголовного дела может идти в разрез с принципом презумпции невиновности и лишать гражданина юридической защиты: в то время как лицо, в отношении которого возбуждено уголовное дело, еще не имеет статуса подозреваемого, в отношении него могут приниматься меры, ограничивающие его конституционные права, в частности, право на свободное передвижение. Более того, существующая нормативно-правовая база позволяет полностью обходить предварительное 


\begin{tabular}{|c|c|c|c|c|c|c|}
\hline \multirow{4}{*}{ Impact Factor: } & ISRA (India) & $=3.117$ & SIS (USA) & $=0.912$ & ICV (Poland) & $=6.630$ \\
\hline & ISI (Dubai, UAE & $=0.829$ & РИНЦ (Russia) & $=0.156$ & PIF (India) & $=1.940$ \\
\hline & GIF (Australia) & $=0.564$ & ESJI (KZ) & $=\mathbf{5 . 0 1 5}$ & IBI (India) & $=4.260$ \\
\hline & JIF & $=1.500$ & SJIF (Morocco) & $=5.667$ & OAJI (USA) & $=0.350$ \\
\hline
\end{tabular}

расследование, наделяя правоохранительные органы правом проводить доследственные проверки, административные проверки и иные действия, в ходе которых можно получить те же сведения, не предоставляя при этом подследственным лицам никаких процессуальных гарантий [8, с. 52].

Следует отметить, что основной целью принятия нового уголовно-процессуального кодекса является упрощение и повышение экономичности уголовного судопроизводства и упразднение стадии возбуждения уголовного дела, на наш взгляд, лишь положительно отразится на соблюдении конституционных прав граждан и исключит «излишнюю волокиту» в виде проведения большого объема мероприятий, предшествующих возбуждению уголовного дела в рамках так называемой «соответствующей проверки» [9, ст. 56]. При этом, законодатель не конкретизирует, какие процессуальные действия должны составлять содержание «соответствующей проверки», заметьте, даже не применяется термин «доследственная проверка», а «соответствующая проверка». Данный термин является достаточно аморфным, что позволяет толковать каждому по-своему, что абсолютно недопустимо в уголовно-процессуальной деятельности.

Кроме того, для проведения так называемой «соответствующей проверки», законодателем предусмотрены сроки. Так, в соответствии со ст. 156 УПК КР от 1999 года, решение о возбуждении уголовного дела или об отказе в его возбуждении должно быть принято в трехдневный срок, а по материалам, требующим дополнительной проверки, - в срок не более десяти дней.

В случае невозможности принятия решения в указанные сроки этот срок может быть продлен прокурором до одного месяца по мотивированному постановлению следователя. Данное обстоятельство свидетельствует о затягивании сроков рассмотрения заявлений, сообщений о преступлениях, с одной стороны, и увеличение отрыва времени с момента совершения преступления до принятия решения о возбуждении уголовного дела, с другой стороны.

Кроме этого, никому не секрет, что под «соответствующей проверкой», практически проводится расследование, то есть это «соответствующая проверка» превращается в «суррогат расследования». При этом, имеем:

- за период проверки, лицо, написавшее заявление не обладает никаким статусом, соответственно не имеет никаких процессуальных прав для защиты своих интересов;

- уголовное дело официально не возбуждено, но проводятся процессуальные действия, которые в принципе могли бы быть проведены в рамках расследования;

- происходит дублирование определенных процессуальных действий, то есть граждане сначала подробно опрашиваются, а затем, после возбуждения уголовного дела, вновь вызываются на допрос

УПК 1999 года, классифицировал стадии уголовного процесса на три вида: на досудебные, судебные и исключительные, где к досудебным стадиям относились: стадия возбуждения уголовного дела и стадия производства следствия. Учитывая, что новый УПК КР упразднил стадию возбуждения уголовного дела, нет смысла одну стадию- стадию производства следствия выделять в самостоятельную стадию. Исходя из этих соображений, законодатель, досудебную стадию, то есть с момента поступления заявления, сообщения о совершенном или готовящемся преступлении до направления уголовного дела прокурору с обвинительным актом назвал досудебным производством.

Если обратимся к УПК КР 1999 года, в ст.5 «Определение основных понятий, содержащихся в настоящем Кодексе», под досудебным производством понимается уголовное судопроизводство с момента получения сообщения о преступлении до направления прокурором уголовного дела в суд для рассмотрения его по существу. Это же понятие в новом УПК КР определено следующим образом: «досудебное производство - уголовное судопроизводство с момента регистрации заявления, сообщения о преступлении и (или) проступке в Едином реестре преступлений и проступков до направления прокурором материалов дела в суд для рассмотрения его по существу» (ст. 5 УПК КР). Таким образом, если по УПК КР 1999 года, началом уголовного судопроизводства считалось принятие решения о возбуждении уголовного дела путем вынесения соответствующего постановления, то новый УПК КР отошел от этих правил и внедрил, так называемое «автоматическое начало досудебного производства». Так, согласно ст. 149 УПК КР, уполномоченное должностное лицо органа дознания, следователь, прокурор безотлагательно, не позднее 24 часов с момента получения заявления, сообщения о совершенном преступлении либо проступке или при непосредственном обнаружении обстоятельств, которые свидетельствуют о совершенном преступлении, проступке, при поступлении выделенных материалов уголовных дел и дел о проступках, а также при поступлении материалов досудебного производства из иностранного государства обязаны внести соответствующие сведения в Единый реестр преступлений и 


\begin{tabular}{|c|c|c|c|c|c|c|}
\hline \multirow{4}{*}{ Impact Factor: } & ISRA (India) & $=3.117$ & SIS (USA) & $=0.912$ & ICV (Poland) & $=6.630$ \\
\hline & ISI (Dubai, UAE & $=0.829$ & РИНЦ (Russia & $=0.156$ & PIF (India) & $=1.940$ \\
\hline & GIF (Australia) & $=0.564$ & ESJI (KZ) & $=\mathbf{5 . 0 1 5}$ & IBI (India) & $=4.260$ \\
\hline & JIF & $=1.500$ & SJIF (Morocco & $=5.667$ & OAJI (USA) & $=0.350$ \\
\hline
\end{tabular}

проступков. При этом, под Единым реестром преступлений и проступков следует понимать электронную базу данных, в которую вносятся сведения о начале досудебного производства, процессуальных действиях, движении уголовного дела и (или) дела о проступках, заявителях и участниках уголовного судопроизводства [9, ст.5].

\section{Conclusion}

Таким образом, по новому УПК КР, началом уголовно-процессуальной деятельности считается внесение сведений (заявлений, сообщений о совершенных или готовящихся преступлениях) в Единый реестр преступлений. При таком раскладе дел, решаются следующие задачи:

-более эффективно защищены права, свободы и законные интересы потерпевших от преступления и проступков;

-созданы условия для обеспечения в полном объеме прав лиц, подозреваемых в совершении преступления;

-ограничены в процессуальных правах следователь, прокурор, так введен институт следственного судьи, что соответственно и ужесточает судебный контроль в досудебном производстве, пресекая разного рода нарушения норм УПК КР, произволы и необоснованные решения уполномоченных должностных лиц органа дознания - по делам о проступках, следователя - по преступлениям и прокурора.

При УПК КР 1999 года, суть основных нарушений прав потерпевших сводилась к следующему:

- необоснованный отказ в возбуждении уголовного дела;

- необоснованный отказ в признании лица потерпевшим;

- необоснованное принятие решения прокурором об отмене постановления следователя о возбуждении уголовного дела.
Априори, стадия возбуждения уголовного дела была лишь инструментом манипулирования уголовной статистики. Как показывает практика, следователи возбуждают уголовные дела только в том случае, если видят «перспективу» дела, при «бесперспективных» делах, они начинают отговаривать пострадавших от совершенного деяния «отказаться от подачи заявления» или «помириться с виновным». Бесперспективные дела, безусловно, могут негативно отразиться на «проценте раскрываемости преступлений», что может повлечь за собой и наступление негативных последствий для следователя в виде дисциплинарных наказаний.

Снятие искусственного барьера в виде формального возбуждения уголовного дела, обязывает должностных лиц незамедлительно, своевременно и в обязательном порядке принять и зарегистрировать каждое сообщение, заявление лиц о совершенном или готовящемся преступлении, или проступке в Едином реестре преступлений и проступков. Разумеется, внесение сведений в Едином реестре преступлений и проступков не гарантирует раскрытия всех преступлений и направления их в суд, но хотя бы значительное количество пострадавших от преступлений не будут лишены надежды на расследование их дела. Более того, они могут самостоятельно уже с помощью определенного кода заходить в базу данных и следить за движением своего дела, чего нельзя сказать при УПК КР 1999 года. К примеру, при отказе в возбуждении уголовного дела, лишь единицы решались на подачу жалобы, многие оставались один на один со своими проблемами, что было весьма удобно для следственных подразделений для создания видимости стабильной криминогенной обстановки в стране.

\section{References:}

1. (2017). Ugolovno-protsessualnyiy kodeks Kyirgyizskoy Respubliki ot 2 fevralya 2017 goda \# 20 (Vvoditsya v deystvie Zakonom KR ot 24 yanvarya 2017 goda \# 10 s 1 yanvarya 2019 goda).

2. Vitsyin, S. E. (2003). Institut vozbuzhdeniya ugolovnogo dela $\mathrm{v}$ ugolovnom sudoproizvodstve. Rossiyskaya yustitsiya, \#8, 56.
3. Kozhokar, V. V. (2015). Otkaz v vozbuzhdenii ugolovnogo dela: pravovyie mifyi i realii pravoprimeneniya. Vestnik Moskovskogo universiteta MVD Rossii, \# 3, 63-66.

4. Aleksandrov, A. S., \& Grachev, S. A. (2015). Proekt novogo poryadka otkryitiya ugolovnogo rassledovaniya po soobscheniyu o prestuplenii. Ugolovnyiy protsess, \# 7, 14-21. 


\begin{tabular}{|c|c|c|c|c|c|c|}
\hline \multirow{4}{*}{ Impact Factor: } & ISRA (India) & $=3.117$ & SIS (USA) & $=0.912$ & ICV (Poland) & $=6.630$ \\
\hline & ISI (Dubai, UAE & $=0.829$ & РИНЦ (Russia) & $=0.156$ & PIF (India) & $=1.940$ \\
\hline & GIF (Australia) & $=0.564$ & ESJI (KZ) & $=\mathbf{5 . 0 1 5}$ & IBI (India) & $=4.260$ \\
\hline & JIF & $=1.500$ & SJIF (Morocco) & $=5.667$ & OAJI (USA) & $=0.350$ \\
\hline
\end{tabular}

5. Zhogin, N. V., \& Fatkullin, F. N. (1961). Vozbuzhdenie ugolovnogo dela. (p.34). M.: Gosyurizdat.

6. Sokolova, A. A. (2018). Nekotoryie problemyi pravovogo regulirovaniya stadii vozbuzhdeniya ugolovnogo dela. Molodoy uchenyiy, \#49, 167168.

7. (2010). III Ekspertnyiy Forum po ugolovnomu pravosudiyu dlya Tsentralnoy Azii 17-18 iyunya 2010 g. Dushanbe, Tadzhikistan «Organizatsiya po bezopasnosti i sotrudnichestvu $\mathrm{v}$ Evrope Byuro po demokraticheskim institutam i pravam cheloveka»// v sotrudnichestve s Tsentrami OBSE v Ashgabade, Astane i Bishkeke, Byuro OBSE v Tadzhikistane, Koordinatorom proektov OBSE v Uzbekistane pri finansovoy podderzhke Irlandskogo agentstva po mezhdunarodnomu razvitiyu.

8. Banchuk, O. (2010). rukovoditel programm i chlen pravleniya Tsentra politiko-pravovyih reform Ukrainyi. III Ekspertnyiy Forum po ugolovnomu pravosudiyu dlya Tsentralnoy Azii 17-18 iyunya 2010 g. Dushanbe, Tadzhikistan «Organizatsiya po bezopasnosti i sotrudnichestvu v Evrope Byuro po demokraticheskim institutam i pravam cheloveka»// v sotrudnichestve s Tsentrami OBSE v Ashgabade, Astane i Bishkeke, Byuro OBSE v Tadzhikistane, Koordinatorom proektov OBSE v Uzbekistane pri finansovoy podderzhke Irlandskogo agentstva po mezhdunarodnomu razvitiyu.

9. (2017). Ugolovno-protsessualnyiy kodeks Kyirgyizskoy Respubliki ot 2 fevralya 2017 goda \# 20 (Vvoditsya v deystvie Zakonom KR ot 24 yanvarya 2017 goda \# 10 s 1 yanvarya 2019 goda).

10. (1999). Ugolovno-protsessualnyiy kodeks Kyirgyizskoy Respubliki ot 30 iyunya 1999 goda \# 62. 